\title{
Interpreting Metaphor of Modality in Advertising English
}

\author{
Jian $\mathrm{Xu}$ \\ School of Foreign Languages, Jiangsu University, Zhenjiang 212013, China \\ E-mail: xujiayin999@yahoo.com.cn \\ The publication of this research paper is funded by a grant from Jiangsu University for senior research fellows.
}

\begin{abstract}
Based on a review of the historical and current studies on modality, this paper aims at interpreting metaphor of modality and its functions in advertising English according to theories of modality system and metaphor of modality in systemic-functional linguistics with a corpus we have collected. It is pointed out that metaphor of modality, a usual method to scheme modality and allocate modal responsibility, plays pragmatic roles of foregrounding subjectivity and objectivity as well as expressing politeness and text cohesion, hence helping advertisers to establish interpersonal relationship with the readers and to achieve their commercial goals by manipulating them.
\end{abstract}

Keywords: Advertising English, Systemic-functional linguistics, Modality, Modality system, Metaphor of modality, Pragmatic function

\section{Introduction}

Language, coming into existence along with that of human beings, has been developed into an important tool for us to describe our recognition of the objective world and to coordinate interpersonal relationships with the development of human society. Due to the unlimitedness of the objective world and limitedness of human cognition, people tend to spare no effort in leaving themselves leeway in their discourse while guaranteeing transmission of information when they express their recognition and understanding of the objective world with their language. Meanwhile, in the coordination of interpersonal relationships with language, because of the diversity of social activities and the complexity of interpersonal relationships, people sometimes offer or ask for information straightforwardly while sometimes blur their attitudes and opinions in an indirect and polite way. All these are involved in modality.

Researches on modality have gone through a long history, appealing to a lot of linguists, philosophers and logicians. It is over 2000 years ago that ancient philosopher Aristotle remarked on the logical relations between the possibility and necessity of modality. In the later half of the $20^{\text {th }}$ century, with the development of modern linguistics, modality attracted more attention from various linguistic shools, spanning from traditional grammar, semantics, generative grammar, pragmatics, semiotics, cognitive grammar to systemic-functional grammar, and achieved substantial accomplishments. However, there is no agreement about the definition of modality yet. Lyons (1977, p541) pointed out that modality refers to people's opinions and attitudes towards propositions expressed with language or circumstances described by propositions. Quirk (1985, p219) regarded it as the speaker's judgment on the authenticity of propositions. Palmer (1986, p16) claimed that modality is the grammarization of the speaker's subjective attitudes and opinions. Jian Li (1999, p21) defined modality as the degrees between right and wrong. In spite of their differences, all these definitions agreed on the relevance of modality to judgments on possibility. Systemic-functional linguistics represented by Halliday $(1985,1994)$, based on function, sumed these thoeries up and described modality and modality system with the systemic theory and creatively introduced the concept of metaphor of modality, which refuted the opinion that modality is mainly reflected by modal auxiliaries in traditional grammar and extended the socpe of studies on modality, therefore, contributing greatly to researches on the diversity of modality expressions.

Based on the corpus we have collected, this paper employs the theories of modality and metaphor of modality in systemic-functional grammar to analyze metaphor of modality in advertising English to reflect complex semantic connotations and their functions, attempting to reveal how advertisers initiate their discourse with potential customers, establish appropriate interpersonal relationships and achieve their business purposes via metaphor of modality.

\section{Theoretical Basis}

\subsection{Modality System}

As an outcome of human social activities, language plays a variety of functions in human communication. Halliday claims that language has three meta-functions including conceptual meta-function, interpersonal meta-function and textual meta-function, among which interpersonal meta-function pays more attention to the interactive relationship between the author and the expected readers, that is, the speaker expresses his attitudes with his language and exerts influences on the listener's attitudes and behaviors ( Li, 2000, p8). Mood and modality are significant parts in the interpersonal function (Huang, 2001, p79), with the former expressing the speaker's purpose to be achieved with his 
speech while the latter being a semantic system expressing the speaker's judgment or evaluation which covers the field between "yes" and "no", hence adding another meaning to the most neuter semantic value of a proposition (Bybee, 1995, p2).

In his book An Introduction to Functional Grammar (Halliday, 1985, 1994), Halliday combines modality and polarity, that is, defining all the possibilities and states lying between the positive pole ("yes") and the negative pole ("no")as modality. All these states dependent on each other constitute a continuum. In addition, he classifies and describes modality categories systematically (as is shown in Figure 1). When summed up, in systemic-functional grammar, modality is made up of four sub-systems: type, orientation, value and polarity.

First of all, according to different communicative functions, Halliday distinguishes modalization from modulation. The former, belonging to the indicative type, plays a role in information exchange and refers to the speaker's judgment on the possibility and frequency of propositions, including rank of probability (possibly, probably, certainly) and rank of frequency (sometimes, usually, always; the latter, belonging to the imperative type, plays a role in article and service exchange and refers to the speaker's judgment on the expectability of a suggestion, including rank of obligation (allowed, supposed, required) and rank of inclination (willing, keen, determined). Due to the relevance of polarity to value, Halliday assigns low, middle and high values to the above ranks respectively.

Finally, he distinguishes two pairs of orientation including subjectivity and objectivity, explicitness and implicitness. In other words, there are four respective choices in modalization and modulation, including subjective implicit, subjective explicit, objective implicit and objective explicit (Halliday, 1994, p356). Modality orientation is related to the speaker's modal responsibility, that is how much explicit responsibility the speaker takes for his attitudes.(Thompson, 1996, p60)

\subsection{Metaphor of Modality}

It can be revealed that English modality system has its own rules while complexity and uncertainty also exist in the expression of modality meanings, manifested in a variety of means for modalization and modulation. Although modality is mainly expressed by modal verbs and other parts of predicate, they aren't the only means for that. Actually, clauses, nouns, verb phrases or even prepositional phrases can be employed to express modality. The former is regarded as congruent from which is recessive and unmarked; the latter is incongruent form which is dominant and marked, that is, metaphor of modality.

Halliday (1994, p357) claims that it is modality orientation that determines how each modality meaning gets expressed. The relationship between different types of modality and orientation is shown in Table 1 .

It is shown in Table 1 that both the subjective explicit orientation and the objective explicit orientation are based on metaphor, that is, expressions of modality are extended from vocabulary to clauses by adding projecting lauses. However, the subjective implicit orientation and the objective implicit orientation are non-metaphorical modality forms, which are expressed by modal verbs, modal adverbs or predicate extensions. Dongchun Chen (2007) summarizes a table of cognitive and agent modal verbs (Chen, 2007, p94) commonly used to compose modality metaphor clauses from the perspectives of type, metaphor and meaning. It is easy to find that in the subjective explicit orientation, clauses expressing modality are mainly used to express a psychological process to give prominence to the speaker's subjective opinions and to make them responsible for their judgments or suggestions while in objective explicit, such clauses generally express a decorative relational process and therefore the speaker's opinions will be lighted and his relevant responsibility will be avoided. Besides, nominalization of modality can also be employed to express the objective explicit orientation. (Chang, 2001, p8) Nouns of this kind include possibility, probability, likelihood, certainty, regularity, intention, desire, determination, need, obligation and so on. By building modality into undeniable facts, the advertiser will succeed in hiding the source of modality and make it objective and explicit. In addition, some prepositional phrases can also be used to express modality, such as in my opinion, to my mind in the expression of subjective explicit and in all probability, to some extent in the expression of objective explicit. (Thompson, 1996, pp60-63) Certainly, we cannot separate metaphorical expressions from congruent ones sharply because they are consecutive. Therefore, specific discourse context and the expected effect should be taken into consideration.

In a word, metaphor of modality can arrange information according to modality responsibility in a reasonable way in order to exert the pragmatic functions of modality in discourse and therefore to achieve the purpose of communication effectively.

\section{Metaphor of Modality and Its Functions in Advertising Discourse}

Advertising is a persuasive and dominant communicative activity (Gold, 1987, p121) with the purpose to establish certain relationships between the buyer and the seller to persuade consumers into buying commodities and services. Therefore, the interpersonal function seems particularly important. As a marked manifestation of modality, metaphor will create special interpersonal and discourse effects, hence helping the advertiser to persuade and dominate consumers. 


\subsection{Preposing Subjectivity and Objectivity}

In advertising English, advertisers often need to made some judgments or explanations on their products or enterprises. In order to emphasize their own opinions, they tend to employ the subjective explicit orientation to emphasize the subjective nature of their opinions and take great modality responsibility, as a result, they succeed in emphasizing the core advantage and ideas of their enterprises or products, increasing consumers' understanding about them, satisfying the target clients' demands and taking the dominant place in their communication with consumers. For example:

(1)At Covidien, we believe innovation is the key to helping medical professionals and patients find effective treatment. For more, visit covidien.com.

(The Economist, Sep $13^{\text {th }}-19^{\text {th }}, 2008$ )

\section{(2)Redefining the Way We Live}

...At NTT DOCOMO, we're confident that blue-sky thinking can redefine the way we live our lives---for the better. (Fortune, Feb 23,2009)

In Sample (1), a subjective explicit metaphor expressed by "we believe" emphasizes the advertiser's perseverant pursuit for medical technique innovation, hence fulfilling patients' demands for high-quality medical services. In the modern society filled with illusive advertising, such advertisement will win consumers' trust without any difficulty. Similarly, in Sample (2), NTT DOCOMO expresses its humanistic care for consumers by emphasizing its operation principle to pursue nature and environmental protection, hence shortening the psychological distance between its consumers and it. As a result, they will have strong belief that this company can provide healthy, low-radiation mobile telephone services and be glad to be its consumers.

Sometimes, advertisers may employ objective explicit metaphor on demands, making its judgments or suggestions facts with fixed characteristics or undeniable ones. Consequently, advertisers will hide their real modality source, hence keeping away from their corresponding modality responsibility. For instance,

(3)...It is hoped that the successful candidate will be able to take up the post no later than Easter 2009. (The Economist, June $21^{\text {st }}-27^{\text {th }}, 2008$ )

(4)...it is possible for a skilled master blender to produce a spirit with a balance of character and smoothness that can be just as satisfying as the finest single malts, whilst exceeding them in richness and complexity... (The Economist, July $5^{\text {st }}-11^{\text {th }}, 2008$ )

In Sample (3), the advertiser embodies modality into a projecting clause by employing objective explicit metaphor, impersonalizing its subjective attitudes with indirect and covert orders and grammaticalizing its order sources, hence lightening the pressure on the candidate by the advertiser, avoiding his modality responsibility and therefore avoiding the candidate's possible objection. Sample (4), an advertisement for Johnnie Walker Whisky, intentionally widening the distance between their evaluation on the products and the advertiser himself by employing a sentence "it is possible..." to express a relational process, hence adding the subjective opinion that "to produce a spirit with a balance of character and smoothness that can be just as satisfying as the finest single malts, whilst exceeding them in richness and complexity...". As a result, greater persuasive force can be produced and the advertiser's corresponding responsibility can be avoided.

In addition, nominalization can be employed to express objective modality. For instance,

(5)Chances are your favorite music, film or TV show was produced with our help...

(Fortune, Nov 10, 2008)

(6)The truth is that for many individuals and corporations, a jet makes sound business sense...

(Fortune, May 5, 2008)

In Sample (5) and Sample (6), two advertisements for an electronic product and private airplanes respectively, nominalization is employed to eliminate the advertiser's involvement, keeping the possibility and certainty of modality meanings out of the advertiser's reach. As a result, consumers will find it more reliable since they feel that the advertisement is based on facts instead of the advertiser's subjective opinions.

\subsection{Expressing Politeness}

According to Brown and Levinson's Face-Saving Theory (2003), advertisers' behavior may threaten consumers' negative face. Therefore, in the current fierce competition, they will spare no effort to show their politeness in order to lesson their threat to consumers' face and promote them to buy products.

Subjectivity and objectivity of metaphor of modality play an important coordinating role in the politeness degree of verbal communication. Linguist Leech (1983) proposes the concept of pragmatic scales, according to which indirectness is proportionate to politeness. That is to say, with greater indirectness, there is higher degree of 
politeness.( Leech, 1983, p108) Objective explicit metaphor of modality helps to form a wider distance between advertisers and their evaluations by constructing the participants' concept resources, which causes a wider psychological distance between advertisers and consumers, hence higher degree of politeness. therefore, advertisers tend to employ objective metaphor if they hope to employ equivalent modality expressions while not to sound impolite. For example,

(7) It seems that giving a wide selection of first run movies, music videos, news, games and sports will make your trip relaxing and enjoyable... (Wang, 2007, p48)

In this advertisement for Virgin Atlantic Airliner, objective explicit modality makes consumers feel that the judgment on a proposition doesn't come from the advertiser, lessening their pressure or constraint. Even if they have no interest in the entertainment activities during their trip, they will have no aversion or confusion due to enough leeway has been left.

In addition, the value of metaphor of modality will also influence the politeness degree of advertising. The greater value of modality is shown, the more positive attitudes the advertiser has toward the proposition or suggestion, the lower degree of politeness is given. Conversely, lower value of modality will lead to more euphemistic mood, more options for consumers to decide whether to accept the advertiser's opinions and higher degree of politeness. For example,

(8) Growth. At FedEx, we believe that differentiating your company from the competition is the best way to facilitate growth...

(Fortune, Feb 18, 2008)

(9) Can we find opportunity in the turbulence? We think we can...

(Fortune, Nov 10, 2008)

(10) At Grant Thornton, we understand that the big decisions you have to make are sometimes difficult, often finely balanced, always with you...

(Fortune, Dec 22, 2008)

The above are three advertisements made by FedEx, Lombard Ordier Darier Hentsch Investment Company and Grant Thornton Consultant Company respectively in Fortune. In the three common subjective metaphors of modality, "we believe" has the highest value of modality, "we think" ranks second and "we understand" ranks third. Obviously, Sample (8) gives the strongest mood, expressing the speaker's affirmation and subjective assertion, and leaving little space for readers and therefore revealing lowest degree of politeness. On the contrary, Sample (10) gives the most gentle mood and the highest degree of politeness by expressing the speaker's understanding.

\subsection{Discourse Cohesion}

In English advertising, metaphor of modality offers a strategy for discourse cohesion, that is, proper use of non-congruent modality expressions will achieve a natural and coherent organization of discourse. The nominalization of modal verbs will not only express the objective explicit orientation, but serve as a cohesion signal. For example,

(11) More of what you travel for. Every trip is a chance to discover exciting places and to reconnect with the people who are important to you. At Sheraton Resorts, there are endless opportunities to explore it all. From invigorating theme park rides to serene beach villas. From spa getaways to reef dive outings. Chances are one of our Asia-Pacific Sheraton Resorts will connect you with all of the reasons you love to travel. At Sheraton, you don't just stay here, you belong. (The Economist, July $12^{\text {th }}-18^{\text {th }}, 2008$ )

In this advertisement for Sheraton Resorts, "chances" carries on the text by summarizing all the modality possibilities involved in the above sentences, hence combing the modality meaning in the whole passage as a cohesion means.

In addition, advertisers can choose from a variety of sentence patterns one fit for specific context according to discourse cohesion, information distribution and structural balance and so on. For example,

(12)...To offer the assurance of unmatched quality, we control the total supply chain of our products and demonstrate full GMP accreditation in every process we undertake. It is no wonder our customers trust no other name but Eu Yan Sang. (Time, Feb 25, 2008)

In this advertisement for Eu Yan Sang, the advertiser employs skillfully an objective explicit metaphor form "it is no wonder" in the last sentence, with which, on one hand, the modality source is hidden and therefore objectivity is revealed, on the other hand, its complex sementaic function of cause and effect puts this advertisement into a more cohesive and logical whole.

\section{Conclusion}

From the functional perspective, systemic-functional linguistics represented by Halliday have constructed an open grammatical framework and expanded the scope of research on modality by introducing the concept of metaphor of modality. This liguistic device enables modality to be expressed not only by modal verbs but by nouns, adjectives, prepositional phrases, verb phrases and so on, which is a remarkable breakthrough in functional grammar. (Hu, 2000, p32) The rank shift of sentence and corresponding conversions in grammatical structure and category are regarded as the source of metaphor of modality, which supports the idea that grammar can be constructed in different ways in the 
meaning system and reflects the development in human cognition.

Based on an introduction to Halliday's theory of modality system and with a focuses on metaphor of modality and its functions in advertising English, this paper has reached the conclusion that metaphor of modality can be employed in English advertising to foreground subjectivity and objectivity, to express politeness and to unite discourse into cohesion. With the help of this advanced liguistic device, advertisers can arrange information according to desired modal responsibility in order to avoid relevant legal responsibility and restriction while establish interpersonal relationships with consumers to exert influences on their attitudes as well as behaviors so as to correctly convey their communicative intentions and achieve their commercial purposes.

\section{References}

Brown, R. \& S. Levinson. (1978). The Argument: Intuitive Bases and Derivative Definitions. in Hezhaoxiong. (2003). Selected Reading for Pragmatics. Shanghai: Shanghai Foreign Language Education Press.

Chang, Chenguang. (2001). Interpersonal Grammar Metaphor in English. Foreign Languages and Their Teaching. Vol. 7: pp 6-8.

Chen, Dongchun. (2007). Teaching of English Modality within the Framework of Systemic-Functional Grammar. Journal of Guangdong University of Foreign Studies. Vol.3: pp 91-95.

Fielschman. (1995). Modality in Grammar and Discourse. Amsterdam: John Benjamins.

Gold, P. (1987). Advertising, Politics, and American Culture: From Salesmanship to Therapy. New York: Paragon House Publishers.

Halliday, M.A.K. (1985). An Introduction to Functional Grammar. London: Arnold.

Halliday, M.A.K. (1994). An Introduction to Functional Grammar (2nd edition). London: Arnold.

Huang, Guowen. (2001). Theory and Practice of Discourse Analysis: A Research on Advertising Discourse. Shanghai: Shanghai Foreign Language Education Press.

Hu, Zhuanglin. (2000). An Introduction to Functional Grammar. Beijing: Foreign Language Teaching and Research Press. p32.

$\mathrm{Hu}$, Zhuanglin. Zhu, Yongsheng. et al. (2005). An Introducton to Systemic-Functional Linguistics. Beijing: Beijing University Press.

Leech, G.(1983). Principle of Pragmatics. London: Longman.

Li, Jian. (1999). Modality and Meaning of Modal Auxiliaries. Journal of Foreign Languages. 1999(4): pp19-23.

Li, Zhanzi. (2000). Modality: An Extension from Sentence to Discourse.Foreign Language Research. Vol. 4: pp 7-12.

Lyons, J. (1977). Semantics(Vol. 2).Cambridge: Cambridge University Press.

Palmer, F. R. (1986). Mood and Modality. Cambridge: Cambridge University Press.

Quirk,R. et al. (1985). A comprehensive Grammar of the English Language. London: Longman.

Thompon, G. (1996). Introducing Functional Grammar. Beijing: Foreign Language Teaching and Research Press.

Wang, Qianqian. (2007). A Research on Metaphor in Advertising Language. Journal of Qufu Normal University. 48.

Table 1. Modality orientation and Types (Hu, 2005, p149)

\begin{tabular}{|l|l|l|l|l|}
\hline & $\begin{array}{l}\text { Subjective explicit } \\
\text { (Metaphor of modality) }\end{array}$ & $\begin{array}{l}\text { Subjective } \\
\text { implicit }\end{array}$ & Objective implicit & $\begin{array}{l}\text { Objective explicit } \\
\text { (Metaphor of modality) }\end{array}$ \\
\hline Modalization: Probability & $\begin{array}{l}\text { I think(in my opinion) Mary } \\
\text { knows }\end{array}$ & Mary'll know & $\begin{array}{l}\text { Mary Probably } \\
\text { knows }\end{array}$ & It isn't likely Mary Knows \\
\hline Modalization: Frequency & & $\begin{array}{l}\text { Fred'll sit quite } \\
\text { quiet }\end{array}$ & $\begin{array}{l}\text { Fred usually sits } \\
\text { quite quiet }\end{array}$ & $\begin{array}{l}\text { It's usual for Fred to sit quite } \\
\text { quiet }\end{array}$ \\
\hline Modulation: Obligation & I want John to go & John should go & $\begin{array}{l}\text { John's supposed to } \\
\text { go }\end{array}$ & It's expected that John goes \\
\hline Modulation: Inclination & (I undertake for Jane to help) & Jane'll help & Jane's keen to help & It's pleasure for Jane to help \\
\hline
\end{tabular}




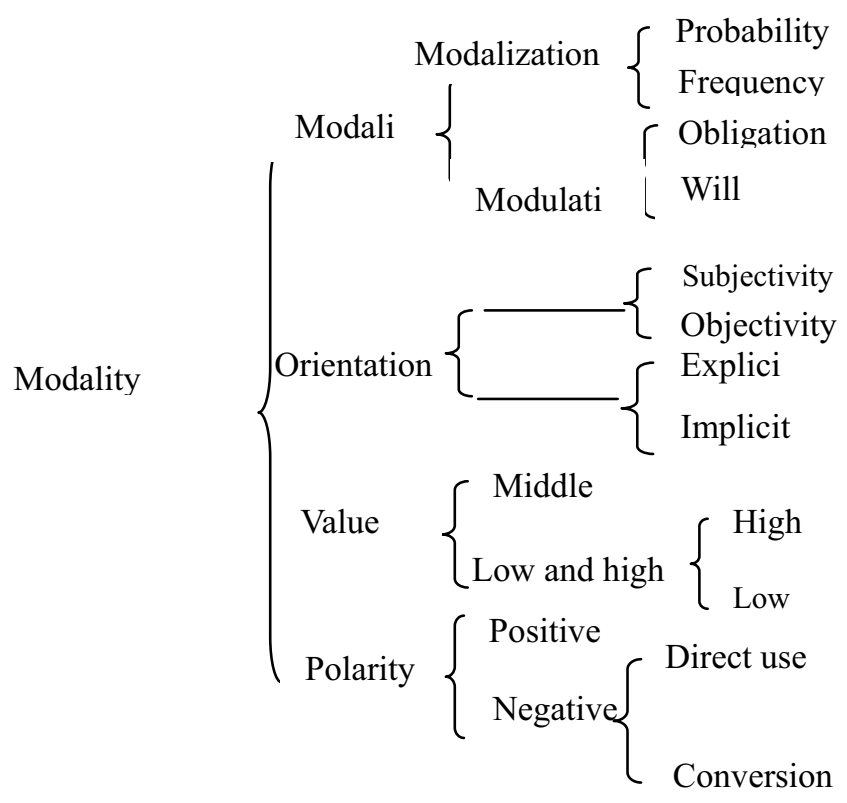

Figure 1. Modality System in Systemic-Functional Grammar (Hu, 2005, p150) 